\title{
CORROSION INHIBITION OF AA6061 AND AA6063 ALLOY IN HYDROCHLORIC ACID MEDIA BY SCHIFF BASE COMPOUNDS
}

\author{
SANAULLA PATHAPALYA FAKRUDEEN ${ }^{a *}$, ANANDA MURTHY H. C $C^{b}$ BHEEMA RAJU $V^{c}$. \\ a," Department of Engineering Chemistry, HKBK College of Engineering, Nagawara, \\ Bangalore -560045, Karnataka, India.Tel: 080-25441722 \\ ${ }^{b}$ Department of Chemistry, $R N$ Shetty Institute of Technology, Channasandra, \\ Bangalore-560061, Karnataka, India. Tel: 080-28603880. \\ 'Department of Chemistry, Dr. Ambedkar Institute of Technology, Mallathahalli, Bangalore - 560056, Karnataka, India. Tel: 080-23211505
}

(Received: December 2, 2011 - Accepted: August 13, 2012)

\begin{abstract}
N, N'-bis (Salicylidene)-1, 4-Diaminophenelyne (SDP) and N, N'-bis (3-Methoxy Salicylidene)-1, 4 Diaminophenelyne (MSDP) were synthesized, and their molecular structure were determined by FT-IR and 'H NMR. The corrosion inhibitions of these compounds on AA6061 in $1 \mathrm{M}$ Hydrochloric acid were evaluated by weight loss method and scanning electron microscopic technique. The weight loss study showed that the inhibition efficiency of these compounds increases with increase in concentration and vary with solution temperature and immersion time. The various thermodynamic parameters were also calculated to investigate the mechanism of corrosion inhibition. The effectiveness of these inhibitors were in the order of MSDP> MDP. The adsorption of Schiff bases on AA6061 and AA6063 alloy surface in acid obeyed Freundlich adsorption isotherm. The surface characteristics of inhibited and uninhibited alloy samples were investigated by scanning electron microscopy (SEM).
\end{abstract}

Keywords Corrosion inhibitors, AA6061 alloy, AA6063 alloy, Hydrochloric acid, Schiff-bases

\section{INTRODUCTION}

Corrosion of aluminum and its alloys has been a subject of numerous studies due to their high technological value and wide range of industrial applications especially in aerospace and house-hold industries. Aluminum and its alloys, however, are reactive materials and are prone to corrosion. A strong adherent and continuous passive oxide film is developed on $\mathrm{Al}$ upon exposure to aqueous solutions. This surface film is amphoteric and dissolves when the metal is exposed to high concentrations of acids or bases ${ }^{[1]}$. Hydrochloric acid solutions are used for acid cleaning, acid de-scaling, chemical and electrochemical etching in many chemical process industries where in aluminium alloys are used. It is very important to add corrosion inhibitors to prevent metal dissolution and minimize acid consumption ${ }^{[2]}$. Most of the efficient acid inhibitors are organic compounds that contain mainly nitrogen, sulfur or oxygen atoms in their structure. The choice of inhibitor is based on two considerations: first it could be synthesized conveniently from relatively cheap raw materials; second, it contains the electron cloud on the aromatic ring or electronegative atoms such as nitrogen, oxygen in relatively long-chain compounds. Numerous organic substances containing polar functions with nitrogen, oxygen, and sulphur atoms and aromatic rings in a conjugated system have been reported as effective corrosion inhibiters for aluminium alloys ${ }^{3-}$ ${ }^{5]}$. Some Schiff bases have been reported earlier as corrosion inhibitors for aluminum alloys ${ }^{[6-8]}$, iron ${ }^{[9-10]}$ and copper ${ }^{[11-12]}$. Compounds with $\pi$-bonds also generally exhibit good inhibitive properties due to interaction of $\pi$ orbital with metal surface. Schiff bases with $\mathrm{RC}=\mathrm{NR}^{\prime}$ as general formula have both the features combined with their structure which may then give rise to particularly potential inhibitors.

The present work is aimed at investigating the inhibitive ability of Schiff bases on corrosion of AA6061 and AA6063 in 1M Hydrochloric acid medium in the temperature range $303-333 \mathrm{~K}$ using weight loss method and scanning electron microscopic technique.

\section{EXPERIMENTAL}

\section{Materials and methods}

Synthesis of Schiff bases

The corrosive medium selected for this study was $1 \mathrm{M}$ hydrochloric acid, which was prepared from analytical grade 37 per cent acid concentrated (Merck ) in double distilled water. The preparation of the Schiff Bases employed in this study was done according to the method used by Zolezzi et. $a l^{[13]}$. The Schiff Bases were prepared by the condensation of respective aromatic aldehydes with each of diamines. All reagents used were of analytical grade procured from Sigma Aldrich. N,N'-bis(Salicylidene)-1,4-Diaminophenelyne(SDP) was prepared by slow addition of Salicylaldehyde $(2 \mathrm{mmol})$ in $30 \mathrm{~mL}$ methanol over a solution of 1,4-Phenylenediamine $(1 \mathrm{mmol})$ in $30 \mathrm{~mL}$ methanol and N,N'-bis(3-MethoxySalicylidene)-1,4-Diaminophenelyne(MSDP) by slow addition of Methoxysalicylaldehyde $(2 \mathrm{mmol})$ in $30 \mathrm{~mL}$ methanol over a solution of 1,4 - Phenylenediamine $(1 \mathrm{mmol})$ in $30 \mathrm{~mL}$ methanol taken in a $250 \mathrm{~mL}$ condensation flask. In each case, 2-3drops of acetic acid was added to the mixture of aldehyde and diamine with stirring at constant temperature $25^{\circ} \mathrm{C}$ for 1 hour. Further the mixture was refluxed for $4-5$ hours on a water bath, heating occasionally to improve the yield of the product. The reaction mixture was cooled to room temperature overnight and the colored compound was filtered off and dried. The compounds were recrystallised with ethanol. The product identity was confirmed via melting points, Fourier transform infrared spectroscopy (FT-IR) and Proton Nuclear Magnetic Resonance ('H NMR). The structure, molecular formula and molecular mass are shown in Table 1.

\section{FT-IR spectroscopy and NMR spectroscopy}

FT-IR spectra of Schiff bases were obtained in $\mathrm{KBr}$ with Fourier transform spectrometer (Interspec 2020, UK), for the detection of various functional groups present in these inhibitors. 1H-NMR spectra run in $\mathrm{CDCl} 3$ on a Bruker spectrospin $300 \mathrm{mHz}$ spectrometer with TMS (Me4Si) as the internal standard and its values are given in ppm (d). The chemical shift was recorded relative to TMS assigned at zero. NMR helps in analyzing the type of protons attached to different groups of the inhibitors used

N, N'-bis (Salicylidene)-1, 4-Diaminophenelyne

Mp: $228^{\circ} \mathrm{C}$, IR $\left(\mathrm{KBr} \mathrm{cm}^{-1}\right): 3450(\mathrm{OH}), 3047(=\mathrm{C}-\mathrm{H}), 1606(\mathrm{C}=\mathrm{N})$.

${ }^{1} \mathrm{HNMR}\left(\mathrm{CDCl}_{3}\right): \delta 6.93-7.42(\mathrm{~m}, 12 \mathrm{H}, \mathrm{ArH}) .8 .66(\mathrm{~s}, 2 \mathrm{H}, \mathrm{N}=\mathrm{CH}), 13.16$ $(\mathrm{s}, 1 \mathrm{H}, \mathrm{OH})$,

Mp: $242^{\circ} \mathrm{C}, \mathrm{N}, \mathrm{N}^{\prime}$-bis (3-Methoxy Salicylidene)-1, 4 Diaminophenelyne IR $\left(\mathrm{KBr} \mathrm{cm}^{-1}\right)$ : 3443(OH), 2996(=C-H), 1606(C=N). 1246(-OCH $)$.

${ }^{1} \mathrm{HNMR}\left(\mathrm{CDCl}_{3}\right): 3.95\left(\mathrm{~s}, 6 \mathrm{H},-\mathrm{OCH}_{3}\right), 6.88-7.36(\mathrm{~m}, 10 \mathrm{H}, \mathrm{ArH}) .8 .67(\mathrm{~s}$, $2 \mathrm{H}, \mathrm{N}=\mathrm{CH}), 13.57(\mathrm{~s}, 1 \mathrm{H}, \mathrm{OH})$,

\section{Aluminium Alloy Specimen preparation}

The cylindrical alloy rods were cut into $18 \mathrm{~mm}$ dia and $3 \mathrm{~mm}$ length circular cylindrical disc specimens using an abrasive cutting wheel. The cylindrical alloy specimens were moulded in cold setting Acrylic resin exposing a surface area of $5.0 \mathrm{~cm}^{2}\left(2.5 \mathrm{~cm}^{2}\right.$ each side $)$ as shown in Fig-4 and 5. Before each experiment, the electrodes were abraded with a sequence of emery papers of different grades $(600,800$, and 1200), washed with double distilled water, degreased with acetone and dried at $353 \mathrm{~K}$ for $30 \mathrm{~min}$ in a thermostated electric oven and stored in a moisture-free desiccator prior to use. The typical chemical composition of AA6061 and AA6063 alloys in weight percentage is shown in Table 2 and 3 . 
Table 1

\begin{tabular}{|c|c|c|}
\hline \multicolumn{1}{|c|}{ Structure and Name } & $\begin{array}{c}\text { Molecular } \\
\text { Formula }\end{array}$ & $\begin{array}{c}\text { Molecular } \\
\text { Mass }\end{array}$ \\
\hline
\end{tabular}

Table-2. Typical Chemical Composition of AA 6061.

\begin{tabular}{|c|c|c|c|c|c|c|c|c|c|c|}
\hline Element & $\mathrm{Cu}$ & $\mathrm{Mg}$ & $\mathrm{Si}$ & $\mathrm{Fe}$ & $\mathrm{Mn}$ & $\mathrm{Ti}$ & $\mathrm{Cr}$ & $\mathrm{Zn}$ & Others & $\mathrm{Al}$ \\
\hline Wt.\% & $\begin{array}{c}0.15 \\
-0.40\end{array}$ & $0.8-1.2$ & $0.4-0.8$ & $0.7 \mathrm{Max}$ & $\begin{array}{c}0.15 \\
\mathrm{Max}\end{array}$ & $\begin{array}{c}0.15 \\
\mathrm{Max}\end{array}$ & $\begin{array}{c}0.04- \\
0.35\end{array}$ & $\begin{array}{c}0.25 \\
\mathrm{Max}\end{array}$ & $0.15 \mathrm{Max}$ & \multirow{2}{*}{ Reminder } \\
\hline
\end{tabular}

Table-3. Typical Chemical Composition of AA 6063

\begin{tabular}{|c|c|c|c|c|c|c|c|c|c|c|}
\hline Element & $\mathrm{Cu}$ & $\mathrm{Mg}$ & $\mathrm{Si}$ & $\mathrm{Fe}$ & $\mathrm{Mn}$ & $\mathrm{Ti}$ & $\mathrm{Cr}$ & $\mathrm{Zn}$ & Others & $\mathrm{Al}$ \\
\hline \multirow{2}{*}{ Wt.\% } & 0.10 & $\begin{array}{c}0.45 \\
-0.90\end{array}$ & \multirow{2}{*}{$0.2-0.6$} & $\begin{array}{c}0.35 \\
\mathrm{Max}\end{array}$ & $\begin{array}{c}0.10 \\
\text { Max }\end{array}$ & $\begin{array}{c}0.10 \\
\text { Max }\end{array}$ & $\begin{array}{c}0.10 \\
\text { Max }\end{array}$ & $\begin{array}{c}0.10 \\
\text { Max }\end{array}$ & \multirow{2}{*}{0.15 Max } & \multirow{2}{*}{ Reminder } \\
\hline
\end{tabular}

Weight loss measurements

The test pieces of Aluminium Alloy 6061 and 6063 samples were weighed up to fourth decimal place using digital electronic balance and the exact specimen weights were noted down. The test samples were immersed in 100 $\mathrm{mL}$ of $1 \mathrm{M} \mathrm{HCl}$ in absence and presence of varying concentration of SDP and MSDP Schiff base inhibitor taken in beaker at different temperature ranges $(303,313,323$ and $333 \mathrm{~K})$ in thermostated water bath. Initial weight of samples were measured before immersion and after specified period of exposed time, each piece was taken out of the test solution, rinsed with double distilled water, dried between two filter papers and weighed again using a digital electronic balance. The difference in weight for an exposed period of 2, 4, 6, 8, and 24 hours was taken as the total weight loss. The experiments were carried out at various concentrations $(100,200,300,400,500$ and $600 \mathrm{ppm})$ of all Schiff base inhibitors. Triplicate samples were used to check reproducibility of results. From the average weight loss results (average of three replicate analyses), the corrosion rate, the percentage of inhibition efficiency ( $\%$ IE) and the degree of surface coverage $(\theta)$ were calculated using equations $(1),(2)$ and $(3)^{[14]}$ :

Corrosion rate $=\Delta \mathrm{W} / \mathrm{AT} \mathrm{mg} / \mathrm{cm}^{2} / \mathrm{h}$

Where ' $\Delta \mathrm{W}$ ' is the weight loss in $\mathrm{mg}$, ' $\mathrm{A}$ ' is the area of the specimen in sq-cm and ' $\mathrm{T}$ ' is the exposure time in hours.

Inhibition efficiency $(\% \mathrm{IE})=\frac{\mathrm{CRo}-\mathrm{CR} i}{\mathrm{CRo}} \quad \mathrm{X} 100$

Where, $\mathrm{CRo}=$ Corrosion rate in blank Hydrochloric acid $\mathrm{CRi}=$ Corrosion rate after adding inhibitors

Degree of Surface Coverage $(\theta)=\frac{W_{1}-W_{2}}{W_{1}}$

Where $W 2$ and $W 1$ are the weight losses (mg) for aluminium alloys sample in the presence and absence of the inhibitor and $\theta$ is the degree of surface coverage of the inhibitor.

The percentage of inhibition efficiency ( $\%$ IE) and the degree of surface coverage $(\theta)$ were tabulated.

Scanning electron microscopy

A scanning electron microscope (SEM) [Model No JSM-840A-JEOL] was used to study the morphology of the corroded surface in the presence and absence of inhibitors. The specimens were thoroughly washed with double distilled water before examination. To understand the morphology of the aluminium surface in the absence and presence of inhibitors, the following cases were examined.

(i) Polished aluminium specimen.

(ii) Aluminium specimen dipped in $1 \mathrm{M} \mathrm{HCl}$

(iii) Aluminium alloy specimen dipped in $1 \mathrm{M} \mathrm{HCl}$ containing $500 \mathrm{ppm}$ of Schiff base inhibitor.

\section{RESULTS AND DISCUSSION}

The Schiff base compounds inhibited corrosion rate of aluminium alloys AA6061 and AA6063 in $1 \mathrm{M} \mathrm{HCl}$ at all concentrations under study. Inhibition efficiency increases with increase in inhibitor concentration from 100 to 500 ppm, as shown in Figs. 1(a) and 1(b). The maximum inhibition efficiency was achieved at $500 \mathrm{ppm}$ and a further increase in inhibitor concentration caused no appreciable change in performance. The effect of immersion time on inhibition efficiency is shown in Figs. 2(a) and (b). All the tested Schiff bases show a decrease in inhibition efficiency with increase in immersion time from 2 to 24 hours. This indicates desorption of the Schiff Base over a longer test period and may be attributed to various other factors such as increase in cathodic reaction or increase in ferrous ion concentration ${ }^{[15]}$. The influence of solution temperature on inhibition efficiency is shown in Figs. 3(a) and (b). The inhibition efficiency for all the Schiff base compounds decreases with increase in temperature from 303 to $333 \mathrm{~K}$. The decrease in inhibition efficiency with rise in temperature may be attributed to desorption of the inhibitor molecules at higher temperatures. The degree of surface coverage $(\theta)$ for different inhibitor concentrations in $1 \mathrm{M} \mathrm{HCl}$ at $303 \mathrm{~K}$ after 2 hours immersion time was evaluated from weight loss values.

The experimental data of weight loss $(\Delta \mathrm{w})$, Percentage of Inhibition Efficiency (\% IE), Corrosion Rate (C.R.) and degree of Surface Coverage $(\theta)$ for AA6061 and AA6063 in $1 \mathrm{M} \mathrm{HCl}$ and presence of various concentration of SDP and MSDP Schiff bases at different exposure time and different temperature are shown in Table. 4. 


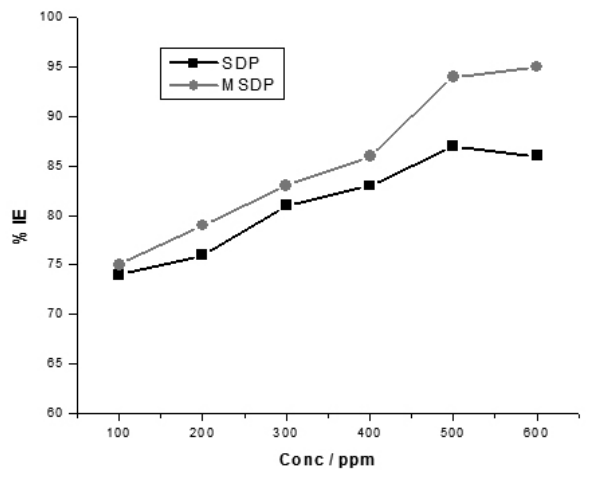

Fig 1(a)

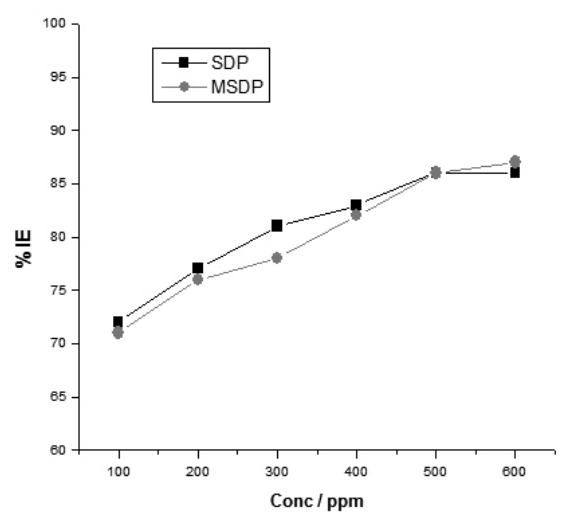

Fig 1(b)

Fig-1. Showing Variation of Inhibition efficiency with inhibitor concentration a) AA6061-SDP and MSDP, b) AA6063-SDP and MSDP

Table-4: Weight loss data of AA6061 and AA6063 in 1M HCl (Blank) and in presence of various concentrations of SDP and MSDP inhibitors at different temperatures-2hours exposure time.

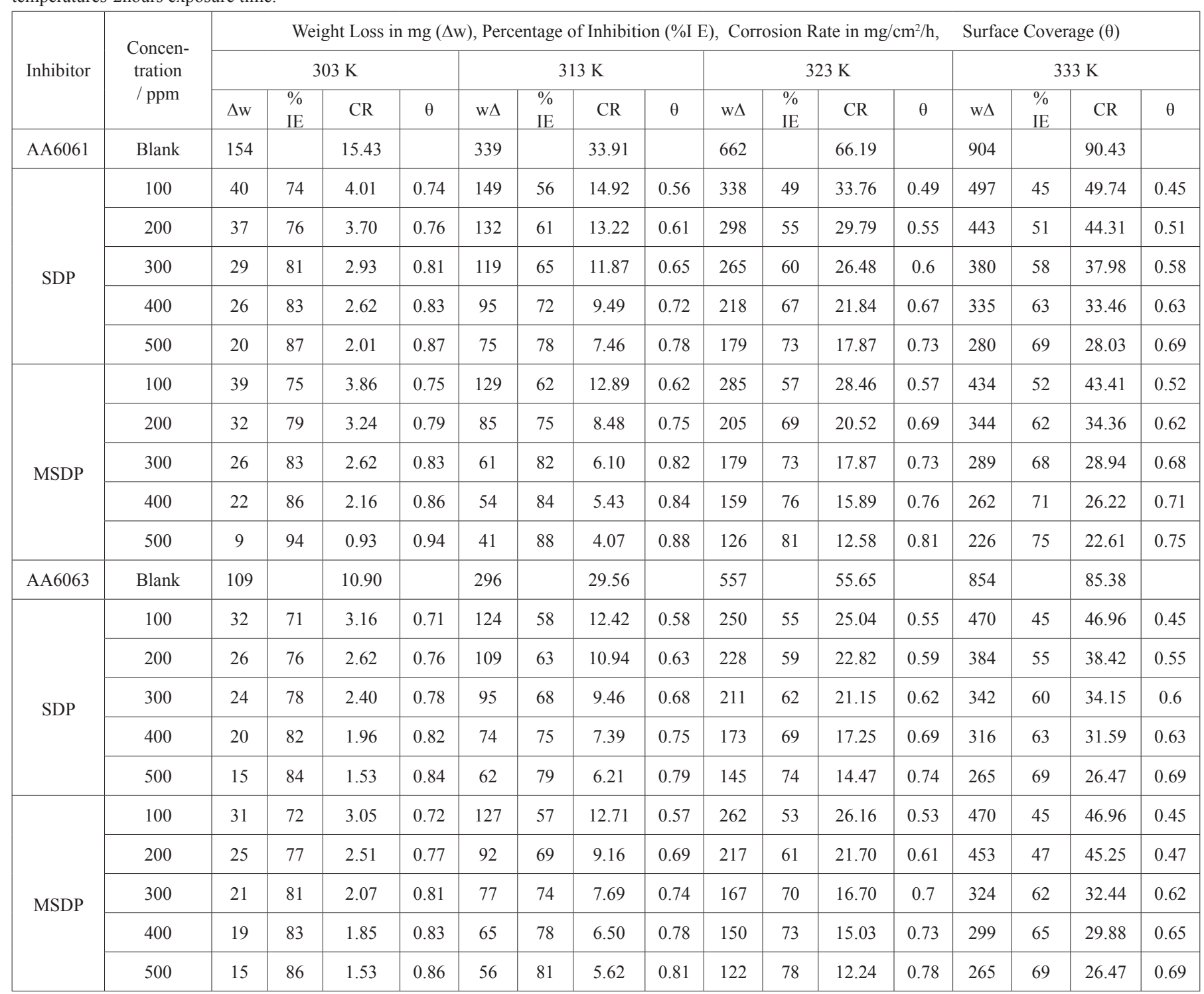




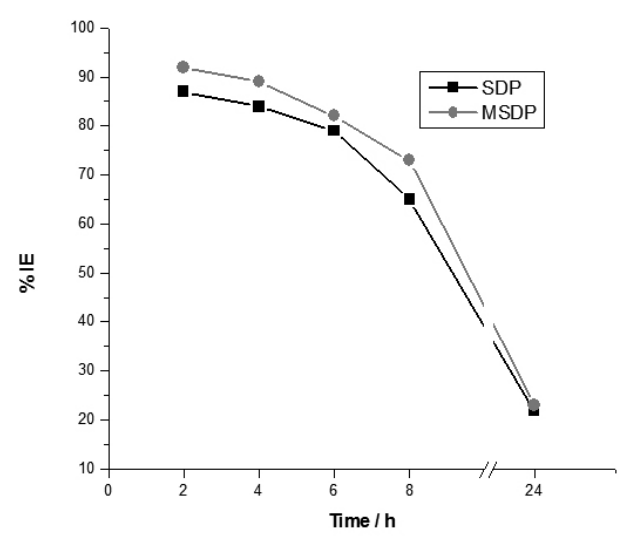

Fig 2(a)

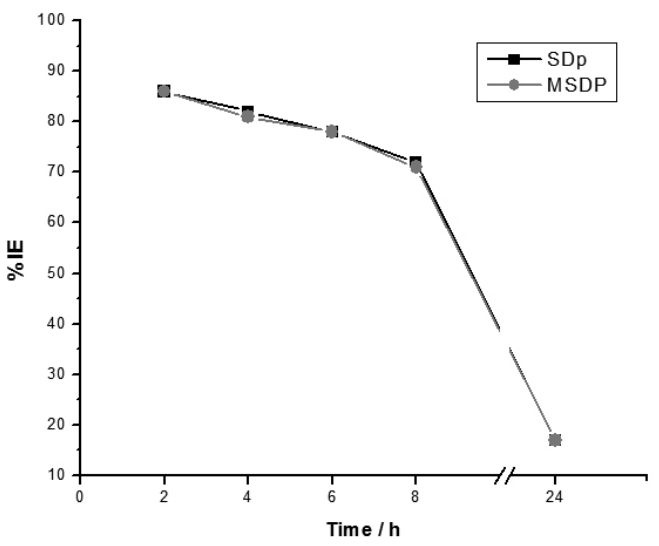

Fig 2(b)

Fig-2. Showing Variation of Inhibition efficiency with immersion time at a concentration of 500ppm and at 303K. a) AA6061-SDP and MSDP b) AA6063SDP and MSDP

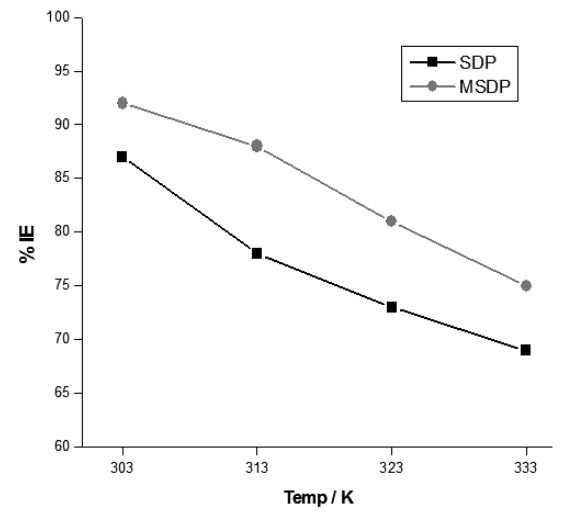

Fig 3(a)

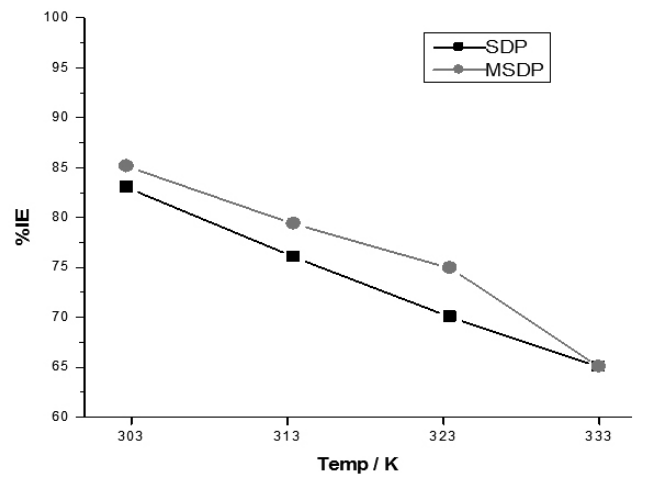

Fig 3(b)

Fig-3. Showing Variation of Inhibition efficiency with temperature at a concentration of 500ppm.. a) AA6061-SDP and MSDP

b) AA6063- SDP and MSDP

Thermodynamic activation parameters

The degree of surface coverage $(\theta)$ for different inhibitor concentrations in $1 \mathrm{M} \mathrm{HCl}$ at $303 \mathrm{~K}$ after 2 hours immersion time was evaluated from weight loss values. The data were tested graphically by fitting to various isotherms. A plot of $\log (\theta / 1-\theta)$ versus $1 / \mathrm{T}$ is shown in Figs. 4(a) and 4(b). The heat of adsorption (Q) was calculated from the slope $(-\mathrm{Q} / 2.303 \mathrm{R})$ of the plot and are given in Tables 5 and 6 . The values of heat of adsorption $\left(<-40 \mathrm{~kJ}\right.$ mol $\left.{ }^{-1}\right)$ suggest physical adsorption ${ }^{[16]}$. A number of authors ${ }^{[17,18,19]}$ have reported that, in acid solution, the logarithm of the corrosion rate is a linear function of $1 / \mathrm{T}$ (Arrhenius equation):

$$
\log (\mathrm{CR})=-\mathrm{E} \text { a } / 2.303 \mathrm{RT}+\mathrm{A}
$$

Where, Ea is the apparent effective activation energy, $\mathrm{R}$ is the universal gas constant and A is the Arrhenius pre exponential factor. Plots of logarithm of corrosion rate obtained by weight loss measurement versus 1/T gave straight lines as shown in Figs. 5(a) and 5(b).

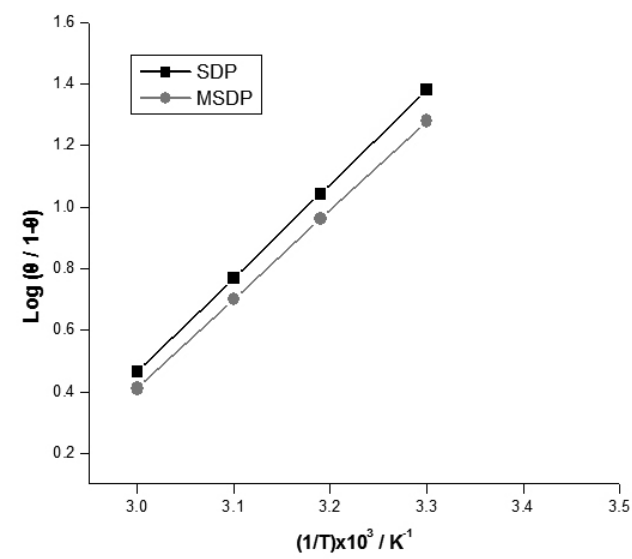

Fig $4($ a)

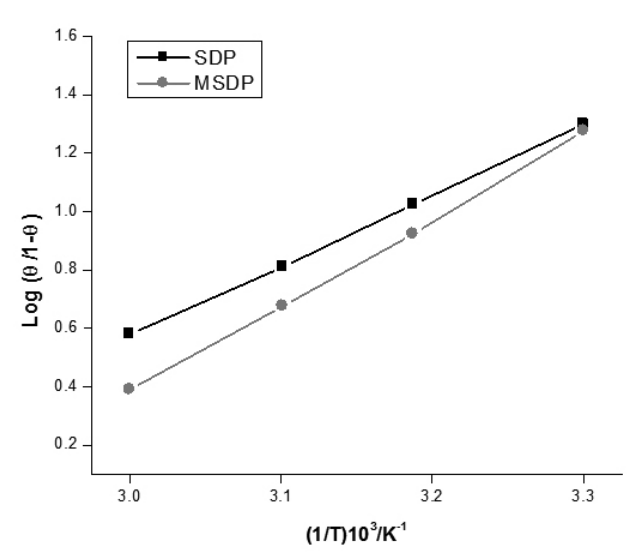

Fig 4(b)

Fig-4. Plots of $\log (\theta / 1-\theta)$ vs. 1/T in Presence of SDP and MSDP at a concentration of 500ppm for, (a) AA6061 and (b) AA6063 


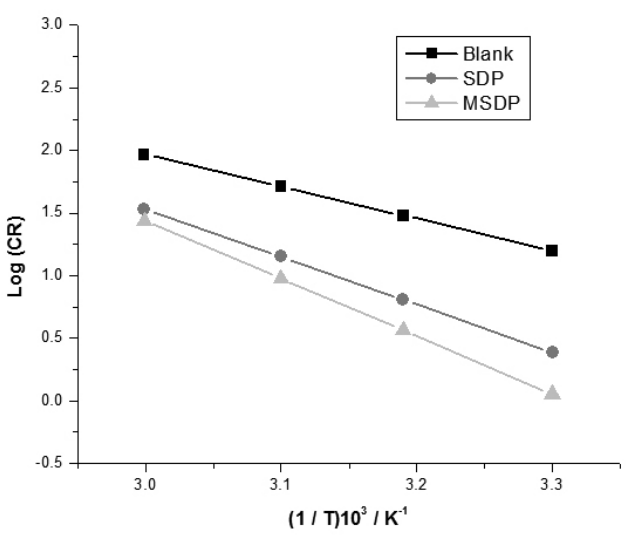

Fig 5(a)

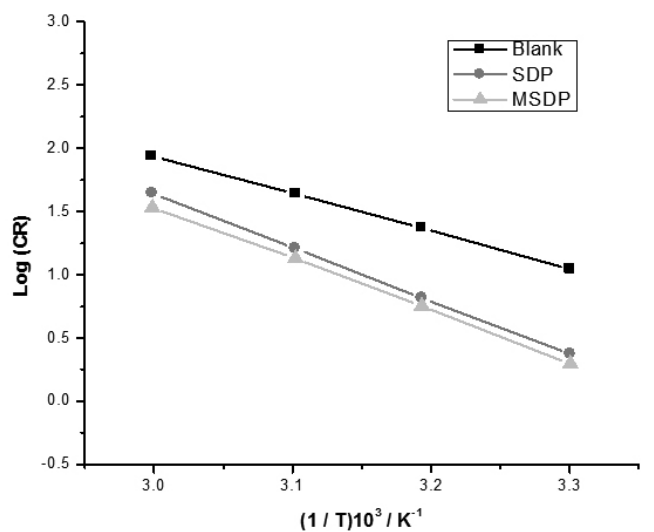

Fig 5(b)

Fig-5. Plots of $\log (\mathrm{CR})$ vs. 1/T in Presence of SDP and MSDP at a concentration of 500ppm for. (a) AA6061 and (b) AA6063

The thermodynamic parameters (Table 5 and 6 ) show that the values of the activation energy Ea are higher for inhibited system as compared to the uninhibited system (Blank) suggesting that dissolution of aluminium alloys is slow in the presence of inhibitors. It is known from the Equation (4) that the higher Ea values lead to the lower corrosion rate. This is due to the formation of a film on the surface of aluminium alloys, which serves as a protective barrier. The inhibition efficiency follows the order: MSDP $>$ SDP for AA6061 and AA6063. From the values of thermodynamic parameters, it is observed that the inhibitors are effective at lower temperatures.

An alternative formula for the Arrhenius equation is the transition state equation ${ }^{[20,21]}$ (5):

$$
\mathrm{C} . \mathrm{R}=\underline{\mathrm{RT}} e^{(\Delta \mathrm{S} / \mathrm{R})} e^{(-\Delta \mathrm{H} / \mathrm{RT})}
$$

Where, $\mathrm{h}$ is the Plank constant, $\mathrm{N}$ is the Avogadro number, $\Delta \mathrm{S}$ is entropy of activation and $\Delta \mathrm{H}$ is the enthalpy of activation.

A plot of $\log (\mathrm{CR} / \mathrm{T})$ versus $1 / \mathrm{T}$ gave a straight line, (Figs. 6(a) and 6(b)) with a slope of $(-\Delta \mathrm{H} / 2.303 \mathrm{R})$ and an intercept of $[(\log (\mathrm{R} / \mathrm{Nh})+(\Delta \mathrm{S} / 2.303 \mathrm{R})]$, from which the values of $\Delta \mathrm{S}$ and $\Delta \mathrm{H}$ were calculated.

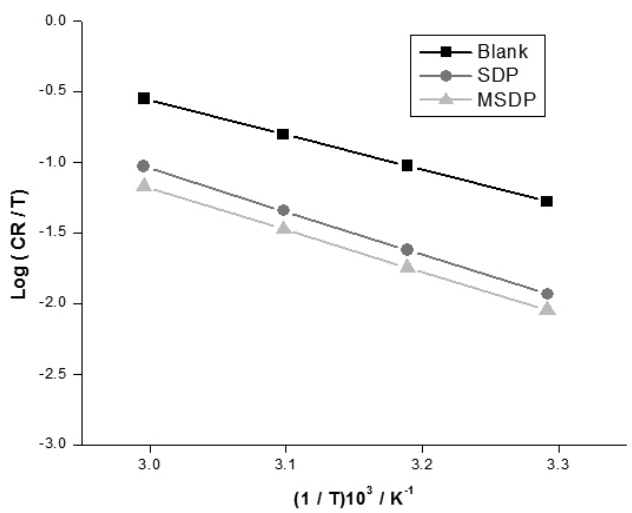

Fig 6(a)

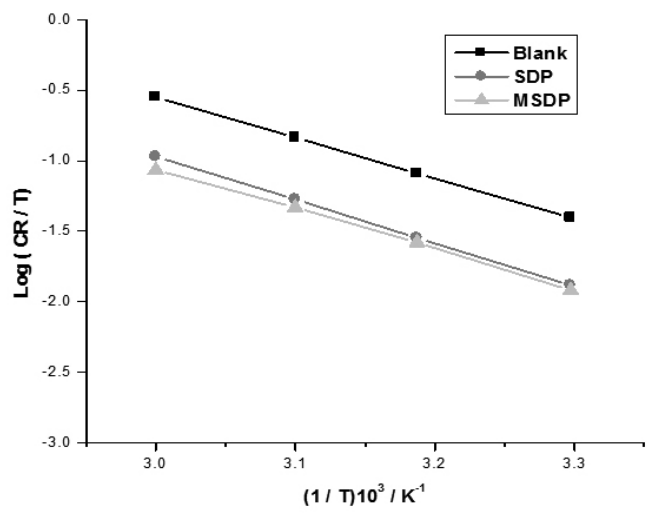

Fig 6(b)

Fig-6. Plots of $\log (\mathrm{CR} / \mathrm{T})$ vs. 1/T in Presence of SDP and MSDP at a concentration of 500ppm at 2 hours immersion time for (a) AA6061 and (b) AA6063

The values of enthalpy of activation, $\Delta \mathrm{H}$ (Table 5 and 6.) follow the order MSDP $>$ SDP for AA6061 and AA6063. The values of $\Delta \mathrm{H}$ are positive; this indicates that the corrosion process is an endothermic. The entropy of activation, $\Delta \mathrm{S}$ in the absence and presence of inhibitors is large and negative indicating that the activated complex in the rate-determining step represents an association rather than a dissociation step. Thus, a greater degree of orderliness appears during its transformation from reactant to activated complex.

Table-5. Thermodynamic activation parameters for dissolution of AA6061 in $1 \mathrm{M} \mathrm{HCl}$ and in presence of 500 ppm of SDP and MSDP inhibitor.

\begin{tabular}{|c|c|c|c|c|}
\hline System & $\mathrm{Ea}\left(\mathrm{kJmole}^{-1}\right)$ & $\Delta \mathrm{H}\left(\mathrm{kJmole}^{-1}\right)$ & $-\Delta \mathrm{S}\left(\mathrm{Jmole}^{-1} \mathrm{~K}^{-1}\right)$ & $-\mathrm{Q}\left(\mathrm{kJmole}^{-1}\right)$ \\
\hline $1 \mathrm{M} \mathrm{HCl}$ & 48.85 & 46.40 & 147.72 & $-\cdots$ \\
\hline $\mathrm{SDP}$ & 74.55 & 56.87 & 77.73 & 35.81 \\
\hline $\mathrm{MSDP}$ & 87.27 & 60.87 & 99.42 & 42.17 \\
\hline
\end{tabular}


Table-6. Thermodynamic activation parameters for dissolution of AA6063 in $1 \mathrm{M} \mathrm{HCl}$ and in presence of $500 \mathrm{ppm}$ of SDP and MSDP inhibitor.

\begin{tabular}{|c|c|c|c|c|}
\hline System & Ea $\left(\mathrm{kJmole}^{-1}\right)$ & $\Delta \mathrm{H}\left(\mathrm{kJmole}^{-1}\right)$ & $-\Delta \mathrm{S}\left(\mathrm{Jmole}^{-1} \mathrm{~K}^{-1}\right)$ & $-\mathrm{Q}\left(\mathrm{kJmole}^{-1}\right)$ \\
\hline $1 \mathrm{M} \mathrm{HCl}$ & 57.06 & 54.44 & 113.95 & $----_{----}$ \\
\hline $\mathrm{SDP}$ & 75.22 & 61.80 & 53.31 & 29.35 \\
\hline $\mathrm{MSDP}$ & 79.13 & 65.13 & 67.23 & 30.63 \\
\hline
\end{tabular}

Adsorption Isotherms

Adsorption plays an important role in the inhibition of metallic corrosion by organic inhibitors. Adsorption isotherms are very important in understanding the mechanism of inhibition of corrosion reaction of metals and alloys. Generally, the adsorption of organic molecules on a metallic surface involves oxygen, nitrogen and sulphur atoms and in some cases, selenium and phosphorus. In Schiff bases, oxygen and nitrogen atoms are responsible for the adsorption. This process may block active sites on metallic surface and hence, decrease the corrosion of the metal. Assuming that the inhibitors adsorbed on the alloy surface decrease the surface available for cathodic and anodic reactions to take place. The nitrogen atoms of the Schiff bases act as the reaction centers (polar function) because of its higher electron density resulting in the formation of a monolayer on the metal surface ${ }^{[22,23]}$. It is generally assumed that the adsorption of the inhibitors on the metal surface is an essential step in the inhibition mechanism ${ }^{[24]}$. To determine the adsorption mode, various isotherms were tested and curve fitting of corrosion data in $1 \mathrm{M} \mathrm{HCl}$ in presence of different concentration of Schiff bases at $303 \mathrm{~K}$ evaluated. A plot of $\log \mathrm{C}$ vs. $\log \theta$ gave a straight line as shown in the Fig 7 (a) and Fig 7(b) and the Freundlich model is the best fitted.

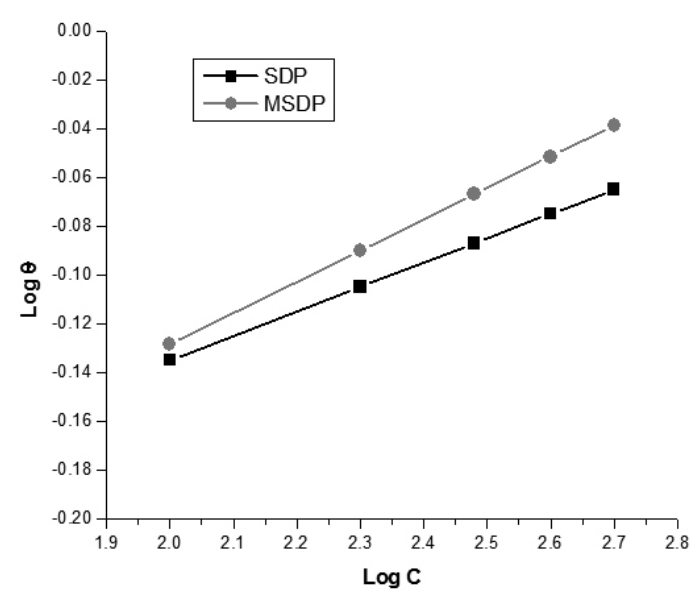

Fig 7(a)

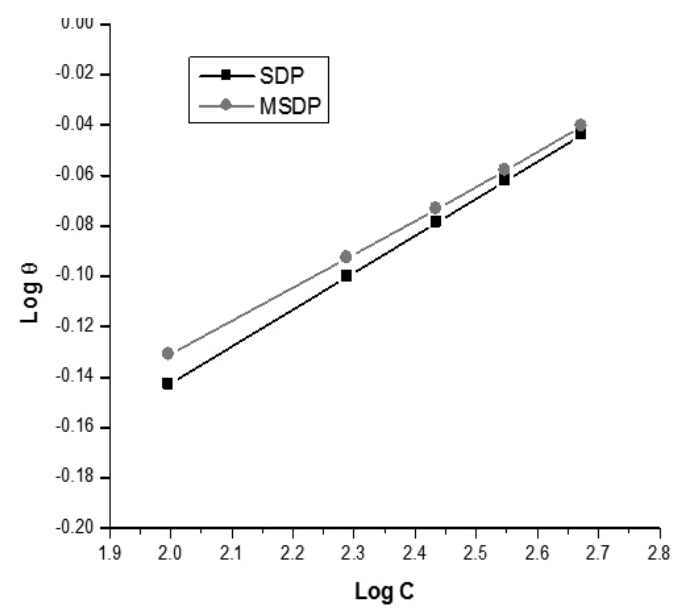

Fig 7(b)

Fig-7. Plots of $\log C$ vs $\log \theta$ in Presence of SDP and MSDP inhibitors at 303K for (a) AA6061 and, (b) AA6063

The Freundlich isotherm is given by ${ }^{[25]}$ equation. (6):

$$
\theta=\mathrm{Ka} \mathrm{C}^{\mathrm{n}}
$$

Where $\mathrm{n}$ is a constant, $\mathrm{C}$ is the inhibitor concentration and $\mathrm{Ka}$ is the equilibrium constant of adsorption process and is related to the standard free energy of adsorption $\Delta \mathrm{G}_{\text {ads }}$ by the equation (7):

$$
\mathrm{Ka}=1 / 55.5 \exp \left(-\Delta \mathrm{G}_{\text {ads }} / \mathrm{RT}\right)
$$

The value of 55.5 is the concentration of water in solution expressed in mole per liter, $\mathrm{R}$ is the universal gas constant and $\mathrm{T}$ is the absolute temperature. To calculate the surface coverage $\theta$ it was assumed that the inhibitor efficiency is due mainly to the blocking effect of the adsorbed species and hence \% IE $=100 \times \theta^{[26]}$. The weight loss results were used to calculate the adsorption isotherm parameters. The surface coverage $(\theta)$ data are very useful while discussing the adsorption characteristics. The plot of $\log \theta$ vs. $\log C$ for all investigated Schiff Base compounds gave a straight line and is characteristic of the Freundlich adsorption isotherm.

Table-7. Adsorption equilibrium constant and adsorption free energy of the Schiff bases adsorbed on AA6061 and AA6063 at 303K.

\begin{tabular}{|c|c|c|c|c|}
\hline \multirow{2}{*}{ Alloy } & Inhibitor & \multicolumn{3}{|c|}{ Freundlich Isotherm } \\
\hline \multirow{4}{*}{ AA6061 } & & $\mathrm{N}$ & $\mathrm{K}_{\mathrm{a}}$ & $-\Delta \mathrm{G}_{\text {ads }} \mathrm{kJmol}^{-1}$ \\
\cline { 2 - 5 } & $\mathrm{SDP}$ & 0.10 & 1.66 & 11.40 \\
\cline { 2 - 5 } & MSDP & 0.13 & 2.20 & 12.11 \\
\hline \multirow{2}{*}{ AA6063 } & SDP & 0.10 & 1.71 & 11.47 \\
\cline { 2 - 5 } & MSDP & 0.13 & 2.04 & 11.92 \\
\hline
\end{tabular}

The free energy of adsorption $\left(\Delta \mathrm{G}_{\mathrm{ad}}\right)$, was calculated, using Equation. (6 and 7), are also given in Table 7. $\Delta \mathrm{G}_{\text {ads }}$ is expressed in $\mathrm{kJ} \mathrm{mol}^{-1}$ of $\operatorname{Org}_{\text {ads }}$. The negative values of $\Delta \mathrm{G}$ ensure the spontaneity of the adsorption process and the stability of the adsorbed layer on the Al surface. It is well known that values of $\Delta \mathrm{G}_{\mathrm{ads}}$ of the order of $40 \mathrm{~kJ} \mathrm{~mol}^{-1}$ or higher involve charge sharing or transfer from the inhibitor molecules to metal surface to form coordinate type of bond (chemisorption); those of order of $20 \mathrm{~kJ} \mathrm{~mol}^{-1}$ or lower indicate a physisorption ${ }^{[27-28]}$. The calculated $\Delta \mathrm{G}_{\text {ads }}$ values are less negative than -20 $\mathrm{kJmol}^{-1}$ indicate, therefore, that the adsorption mechanism of the investigated Schiff bases on aluminium alloy in $1 \mathrm{M} \mathrm{HCl}$ solution is typical of physisorption. The lower negative values of $\Delta \mathrm{G}_{\mathrm{ads}}$ indicate that these inhibitors are not strongly adsorbed on the Al surface. Moreover, $\left|\Delta \mathrm{G}_{\text {ads }}\right|$ of investigated Schiff bases decreases in the order MSDP $>$ SDP for AA6061 and AA6063. This is in good agreement with the ranking of inhibitors efficiency obtained from the different investigated techniques.

\section{Scanning electron microscopy}

Scanning electron microscopy of the AA6061 sample of inhibited and uninhibited metal samples is presented in Fig. 8. The SEM study shows that the inhibited alloy surface is found smoother than the uninhibited surface. 

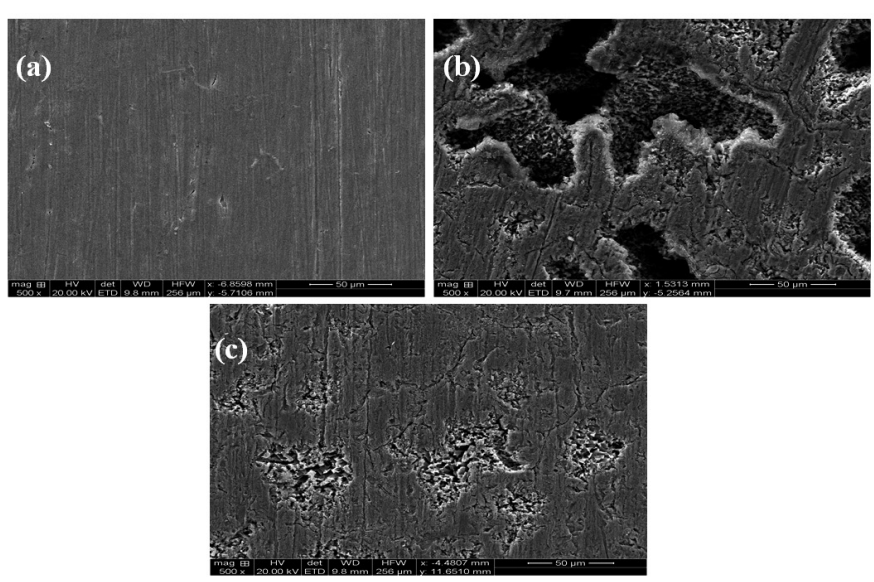

Fig. 8. Scanning electron micrographs of (a) Polished AA6061 alloy, (b) After immersion in $1 \mathrm{M} \mathrm{HCl}$ for $4 \mathrm{~h}$, (c) After immersion in $1 \mathrm{M} \mathrm{HCl}$ for $4 \mathrm{~h}$ in presence of $500 \mathrm{ppm}$ SDP.

\section{Mechanism of corrosion inhibition}

The observation drawn from the different methods, one can conclude that the Schiff base inhibitors are adsorbed on aluminium alloy surface forming a barrier film and protect the alloys in $1 \mathrm{M} \mathrm{HCl}$. The inhibitive action can be explained on the basis of $\mathrm{N}$ and $\mathrm{O}$ atoms in addition to $\pi$ electron interaction of the benzene nucleus with unshared $\mathrm{p}$ electrons of aluminium atoms. The simple concept of coordination chemistry applies in the imine $(\mathrm{C}=\mathrm{N})$ containing ligands where the lone pair of electrons attaches to the central metal ion. The lone pair of electrons on nitrogen is readily available for sharing with metal atoms to form a native covalent bond. Hence, the adsorbed Schiff bases will cover and protect the metal surface from the corrosive environment in $1 \mathrm{M} \mathrm{HCl}$ solution.

There is a general consensus by several authors that the more negatively charged the heteroatom is, more is its ability to adsorb on the metal surface through a donor- acceptor type reaction ${ }^{[29-31]}$.

As far as the inhibition process is concerned, it is generally assumed that adsorption of the inhibitor at the metal/solution interface is the first step in the action mechanism of the inhibitors in aggressive acid media. The adsorption may be the result of one or more of three types of interactions ${ }^{[32,33]}$, namely; electrostatic attraction between charged molecules and charged metal, coordination of the unshared pairs of electron on the molecule to the metal atom, and involvement of $\pi$ electrons of the inhibitor molecule in coordination process.

In general, the investigated Schiff bases may be adsorbed on aluminium alloy surface in their neutral or protonated forms (cationic form). Since it is well known that the aluminum surface is negatively charged in acid solution ${ }^{[34]}$, it is easier for the protonated molecules to approach the negatively charged aluminium alloy surface due to the electrostatic attraction. In case of adsorption, this involves the displacement of water molecules from the aluminium alloy surface and sharing of electrons between the hetero-atoms and aluminium alloy. Also, the inhibitor molecules can adsorb on aluminium alloy surface on the basis of donor-acceptor interactions between $\pi$-electrons of aromatic rings and vacant p-orbitals of surface aluminium atoms. Thus we can conclude that inhibition of aluminium alloy corrosion in $\mathrm{HCl}$ is mainly due to electrostatic interaction. The decrease in inhibition efficiency with rise in temperature supports electrostatic interaction. The adsorption of Schiff base on the aluminium alloy surface can be attributed to adsorption of the organic compounds via phenolic and iminic groups in both cases. Among these two Schiff bases, the chelate effect of MSDP is greater than that of SDP. This is due to the presence of two electron donating groups of $-\mathrm{OCH}_{3}$ in MSDP structure than SDP. The more efficient adsorption of MSDP is the result of electronegative oxygen atoms present in the MSDP compared to SDP Structure. The adsorption of inhibitor SDP and MSDP on aluminum surface is presented by the diagram in Fig :10 a) and $10 \mathrm{~b}$ )

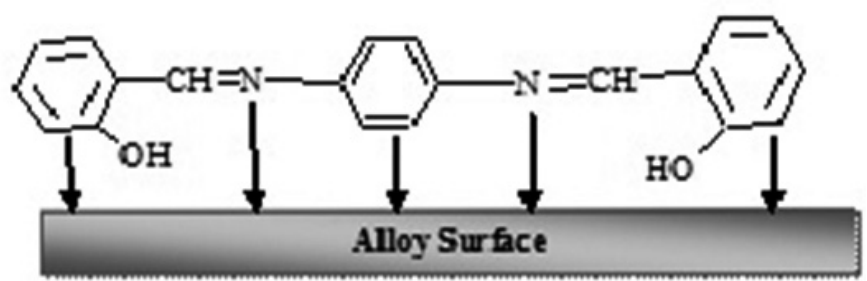

a)

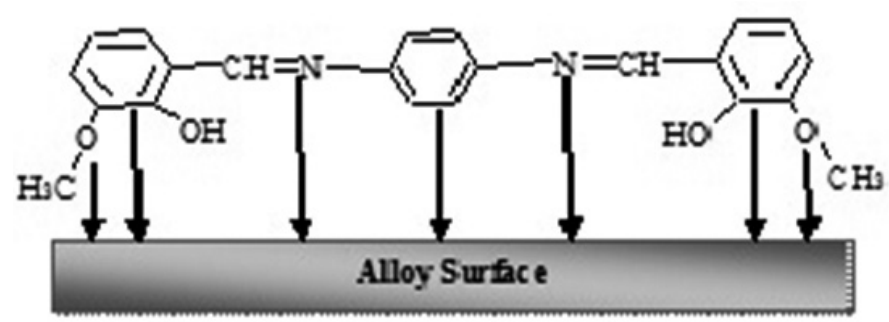

b).

Fig 10: Diagram showing adsorption of inhibitor a) SDP and b) MSDP on aluminium alloy surface.

\section{CONCLUSIONS}

1. The investigated Schiff bases are good inhibitors for aluminium alloys in $1 \mathrm{M} \mathrm{HCl}$ solution.

2. In weight loss studies, the inhibition efficiency (IE) of all Schiff bases increase with increase in inhibitor concentration, whereas decreases with increase in immersion time and temperature.

3. The percentage inhibition (\% IE) in accordance to the order: MSDP $>$ SDP for AA6061 and AA6063.

4. The adsorption of Schiff bases on alloy surface in $1 \mathrm{M} \mathrm{HCl}$ solution follows Freundlich adsorption isotherm.

5. The negative values of $\Delta \mathrm{G}_{\text {ads }}$ shows the spontaneity of the adsorption, suggesting that corrosion inhibition takes place by desorption.

6. Scanning Electron Microscopy (SEM) shows a smoother surface for inhibited alloy samples than uninhibited samples due to formation of protective barrier film.

\section{ACKNOWLEDGEMENTS}

Authors would like to thank for their encouragement to Dr. M.A. Quraishi, Professor of Chemistry, Banaras Hindu University (BHU), Varanasi, India, Dr. D.B. Fakruddin, Professor Emeritus, Siddaganga Institute of Technology, Tumkur, India, and Prof. Lokesh H. B, Dept. of Engineering Chemistry, Vivekananda Institute of Technology, Bangalore, India. Thanks are due to Prof. MN Zulfiqar Ahmed, Dr. Syed Abu Sayeed Mohammed and Mr. Syed Nayazulla of department of Engineering Chemistry, HKBK College of Engineering, for their contribution during the experimental work.

\section{REFERENCES}

1. U.Ergun, D.Yuzer and K.C.Emregul, Mater. Chem.Phys., 109(2008)492499.

2. T.Hurlen, H.H.Lian, O.S.Odegard and T.V.Valand Mater.Chem. Phys.,29(1984)579-585.

3. A.K.Maayta, N.A.F.Al-Rawashdeh, Corros.Sci. 46 (2004) 1129

4. E.E.Oguzie, Mater.Lett. 59 (2005) 1076.

5. A. Popova, M. Chouristov, S. Raicheva, E. Sokolova, Corros. Sci. 46 (2004) 1333.

6. R.G. Nuzzo, E.M. Korenic, L.H. Dubois, J. Chem. Phys. 93, 767 (1980).

7. A.Aytac, U.Ozmen and M.Kabbasakaloglu, Mater.Chem.Phys., 89(2005)176.

8. Hahner, G., Woll, Ch., Buck, M., Grunze, M., 1993. Langmuir 9 (1), 955.

9. H. Shorky, M. Yuasa, I. Sekine, R.M. Issa, H.Y. El-Baradie, G.K. Gomma, Corros. Sci. 40, 2173 (1998). 
10. C.D. Bain, E.B. Thouroughton, Y.T. Tao, J. Evall, G.M. Whiteside, J.G. Nuzzo, J. Am. Soc. 111, 321.

11. Z. Quan, S.H. Chen, Y. Li, X. Cui, Corros. Sci. 44, 703 (2002).

12. S.L. Li, Y.G. Wang, S.H. Chen, R. Yu, S.B. Lei, H.Y. Ma, D.X. Liu, Corros. Sci. 41, 1769 (1999).

13. S. Zolezzi, A Decinti, E. Spodine, Polyhedron 18/6 (1999) 897-904.

14. ASTM (1994) Standard practice for calculation of corrosion rate and related information from electrochemical measurements, annual book of standards, G102-89.

15. Quraishi MA. Rawat J (2001) Corrosion 19: 273.

16. Jha LJ (1990), PhD thesis, University of Delhi, 111.

17. Khedr M. G. A., Lashien M. S., Corros. Sci., 33, 137-140 (1992).

18. Breslin CB, Carrol WM (1993) Corros Sci 34:327.

19. Rehim SSA, Hassan HH, Amin MA(2001) Mater Chem Phys 70:64.

20. H. Eyring, J. Chem. Phys., 3, 107 (1935).

21. Kelth J. Laidler and M. Chrlstlne Klng. J. Phys. Chem. 1983, 87, $2657-$ 2664.

22. Patel, A.S., Panchal, V. A., Shah, N.K., 2010, J. of Pure and App. Sci., 18. 73 .
23. Shah, M. D., Panchal, V. A., Mudaliar, G. V., Shah, N.K., 2011, AntiCorros.

24. A.N.Frumkin, Z.Phys.Chem. 116 (1925) 466].

25. P.W. Atkins, Physical Chemistry, 6th ed., Oxford University Press, 1999, p. 857.

26. Z. Szlarska-Smialowska, Corros. Sci. 18 (1978) 953

27. N. Cahskan, S. Bilgic; Appl. Surf. Sci, 153, (2000),128

28. K. Aramaki, and N. Hackerman; J.Electrochem.Soc.,116, (1969), 568.

29. G. Bereket, C. Ogretic, C. Ozsahim, J. Mol. Struct. (THEOCHEM) 663 (2003) 39

30. W. Li, Q. He, C. Pei, B. Hou, Electrochim. Acta 52 (2007) 6386.

31. S.Rajenran, J.Electrochem.Soc., 54(2)(2005)61.

32. D.Schweinsberg, G.George, A.Nanayakkara, and D.Steiner, Corros.Sci., 28(1988)33

33. S.S.Abd El-Rehim,M.A.Ibrahim and K.F.Khaled, J.Appl.Electrochem., 29 (1999) 593

34. A.K.Vijh, J.Phys.Chem., 72(1968)1148. 